\title{
Dimensions of Creation of the Universe and the Living Worlds
}

\author{
Mahesh M. Shrestha
}

\section{ABSTRACT}

The Cosmos we live in consists of Invisible Prakriti and Visible World. In Visible World, we do live. All the galaxies, Milky Ways, nebulas and planets, stars, and physical bodies belong to this world are governed by the physical and mathematical laws of nature. Prakriti which is invisible spiritually governed and wave-formed existed even before the Big-Bang. Purush holds the Visible World and Prakriti around makes entire Cosmos in existence. Purush which is an absolutely positively charged and quality less with no traces of negative portions always existed, neither being created nor destroyed. A fraction of a Purush known as Omega Point appears into the portion of Prakriti due to some causal effect for further expansion of the Visible World. Purush is situated in the middle of the cylindrical universe surrounded by the Prakriti and Visible World. Theories proposed by different scientists and philosophers to verify the Purush seem to be incomplete trial and error of the zigzag puzzle show. Today, our scientists, cosmologists, and mathematicians are trying to explain the function of the universe through only four physical dimensions of science, which seems to be incomplete without explaining the transcendental factors while dealing with the living bodies.

Keywords: Cosmic mind, Invisible Prakriti or Parallel World, Purush, Visible (Virtual) World.

\author{
Published Online: August 08, 2021 \\ ISSN: $2736-5514$ \\ DOI: 10.24018 /theology.2021.1.4.34 \\ Mahesh M. Shrestha* \\ National Institute of Standards and \\ Technology, Boulder, CO, USA. \\ (e-mail: shresthamahesh08@gmail.com)
}

*Corresponding Author

\section{INTRODUCTION}

In course of the development process before the creation of universe, there existed, since time immemorial, a Purush (also called Shiva, Absolute entity, Cosmic Consciousness) an absolute omnipresent super-conscious immortal entity engulfed the universal truth, space, time, objects, and knowledge in invisible form. This entity possesses a fundamentally Absolute positive (+) behavior, which always remains in a "Singularity" form. This is that formless subjectivity, pure potential, the infinite and universal Consciousness which alone exists even after the cosmic dissolution. Consciousness is the One without the second; the source of everything. The totality of manifestation occupied everything is Consciousness Itself. It is only within this pure, infinite Consciousness, the Potential Plenum, that phenomenal manifestation arose as a mere reflection of that Potentiality, as a mere objective expression of that pure subjectivity. In that original state, call it reality, Absolute, or Nothingness; there is no reason to be aware of anything [1]. So, Consciousness at rest is not aware of itself. The two factors, Purush and Prakriti, though duel in theory, are singular in spirit. Their collective body is just like that of fire. One cannot think of fire without its special thermal value; in the same way one cannot think of Purush without Prakriti in the collective body [8]. The Physicist, Planck, the originator of Quantum Theory, said, "Consciousness, I regard as fundamental. I regard matter as derivative of Consciousness" [5]. Bohr, the father of modern atomic physics, also confirmed that Consciousness was indispensable in quantum physics. Modern physiology is also extending our existence beyond physical limitations [5]. Nobel Prize Laureate Wald indicated, "Consciousness lies outside the parameter of space and time, and it cannot be located, as it has no location. It is all-pervading. Consciousness, therefore, is the potential final field behind the apparent universe comprised of mental as well as material" [5].

On the other side, there is an entity known as Prakriti (called Real or Parallel World) of fundamentally negative (-) in nature having three qualities of cosmic waves or forces such as sentient (sattwa), mutative (rajas) and static (tamas) principles. Sentient is the positive forces whereas static is the negative in nature and mutative is the neutral forces. These three forces produce the thought wave in an entity. Three qualities or forces don't have any physical entity at this stage but could be perceived in course of time as the universe further expands. Due to casual condition a fraction of Purush known as Omega Point appear into the Prakriti becoming aware of itself with sudden feeling of 'I Am'. 'I Am' is the impersonal sense of being aware. It occurs when Consciousness-at-rest transforms to Consciousness-in-action, in other sense when potential energy becomes actual energy. 
The phenomenal objectivity of this pure subjectivity appears and commences in function in our outer world of consciousness in the waking state as a Visible World [1].

Human body also functions as the Cosmos does. All functions which are taking place in the Cosmos are taking place also in a human body, relatively, in micro scale [9]. It is fact that all the minute particles of Visible World functions as Cosmos do. In other word, all matters, and particles, irrespective of dimension, behaves like a universe. Only the difference is in its scope and sizes. This has been confirmed by the elementary particle Higgs-Boson or God Particle discovered in an experiment at CERN (European Organization for Nuclear Research) through the LargeHadrons Collider situated near the border of Geneva and Paris. In the Cosmos each and every matter having size infinitely small tending to zero or tending to infinitely big possesses positive and negative factors in balanced state [7].

In reality, the vibration of words or sounds produces all physical particles and elements in the Visible World. Word is made of different kinds of vibration of strings. If there is a matter or motion or any kind of activities exist, there must be some kinds of sound or bits going on. In bible John 1 says: "In the beginning was the Word, and the Word was with God, and the Word was God. He was with God in the beginning. Through him all things were made; without him nothing was made that has been made." This is recognition that words and language are the basis of all creative acts, and a statement that Jesus Christ is the incarnate expression of God's words and language. Thus, the concept of communication is core to the very nature of God and living things are a reflection of this reality [11]. Depending upon the complexity of matter, the kinds and number of plexuses vary in living beings. There are seven Plexus system to control mental attitudes in a human body. Each Plexus control some cluster of words of sounds known as acoustic roots and corresponding physical organs. With a discipline of meditation one can control these Plexus, and human mind can rise to very higher level beyond Visible World. See Fig. 1 (a) and (b). The meditation process of spiritual science is like a string theory in which Unit Mind of person enters through these strings and reaches near to desired places within no time. String Theory is fundamentally based on materialistic thought only whereas spiritual science with transcendental knowledge has succeeded in describing one step ahead with behavior, feelings and human attitude, life, death, habit, and objective of life etc.

Stephen Hawking and three British astrophysicists in 1970 solved the Equation of General Relativity and produced a deeper solution of the equations. It closes with the SpaceTime Theorem of General Relativity, which states, "If the universe is governed by the equations of General Relativity, not only is we faced with an ultimate origin, but we are also all of the matter in the universe, and all of the energy in the universe. But we're faced with a coincident ultimate origin for even the dimensions of length, width, height and time" [3]. This clearly indicates the importance of transcendental knowledge.

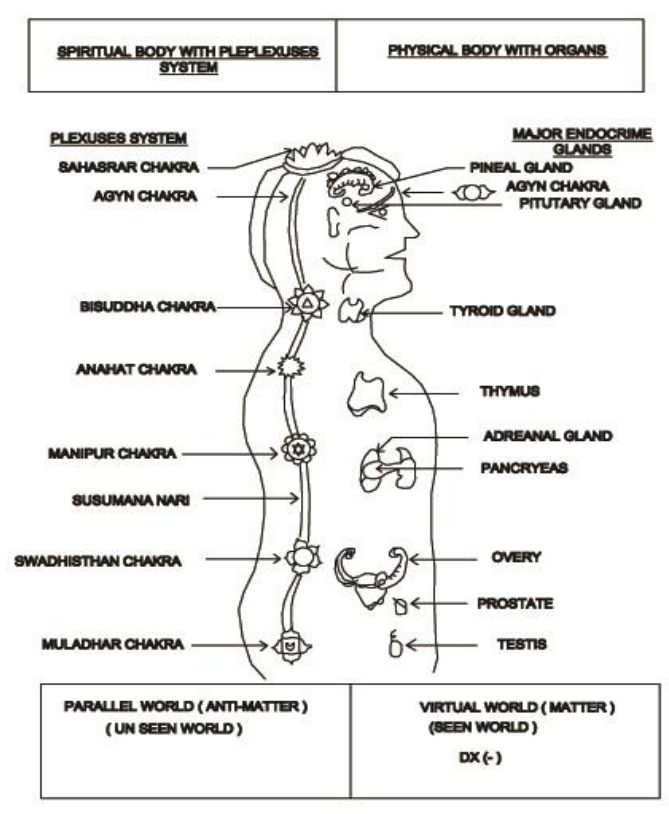

(a)

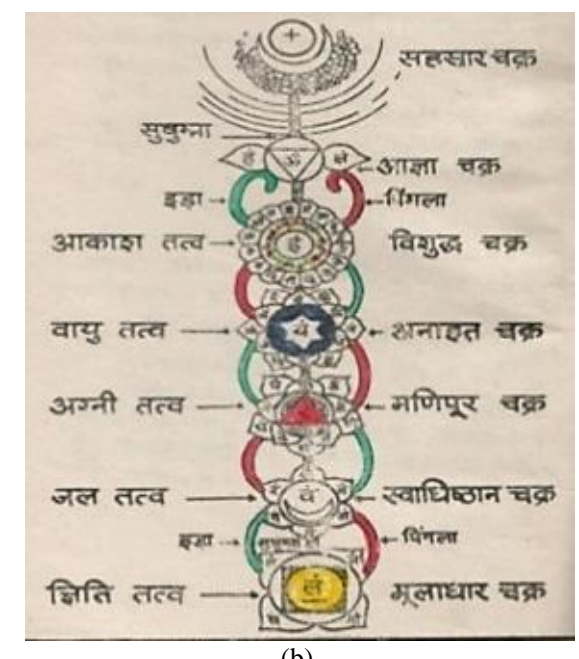

(b)

Fig. $1 \mathrm{a}$ and $\mathrm{b}$. Seven Plexus in human body and their acoustic roots.

\section{MANifESTATION OF PURUSH (COSMIC CONSCIOUSNESS) INTO EXTERNAL WORLD}

The external universe in space-time is a holistic one, where everything is derived from and fundamentally interconnected with all-pervading Cosmic Consciousness. Consciousness is the precondition for all physical and mental faculties (like perception, acting, knowing, thinking, feeling, and willing). First, we become conscious before we perceive, act, know, think, or feel. Consciousness is the elemental condition while all else is secondary to it [5].

\section{A. Purush}

Purush Entity has eternal existence. It is neither created nor destroyed. It is absolutely positively charged entity without negativity. It exists as in the past and at present and will remain as such forever in future with all potentiality. It cannot be produced or generated by any agents. There is in reality no perceiver, perceived or perceptions, no vacuity, no matter, no spirit or Consciousness, but pure cessation or pure negation, and this is what we mean by Purush. Its nature is that of pure 
cessation, and it is this that the Samkhyists call Purush, the Vedantins call Bramh or Shiva, the idealistic Buddhists call "Pure idea" and the Nihilists "Pure-essence less" [12]. The Purush is thus neither existent nor non-existent and is both statical and dynamical. It is indescribable and unnamable and neither being nor non-being nor being-non-being, neither statical being nor becoming. It is situated in such a way that the Prakriti and Visible World cannot reach or touch it. The situation of this entity is supposed to be at the middle of the cylindrical universe (Fig. 2) and all around the cylindrical structure there exists only the Prakriti, Invisible Parallel World and Virtual Visible World [8].

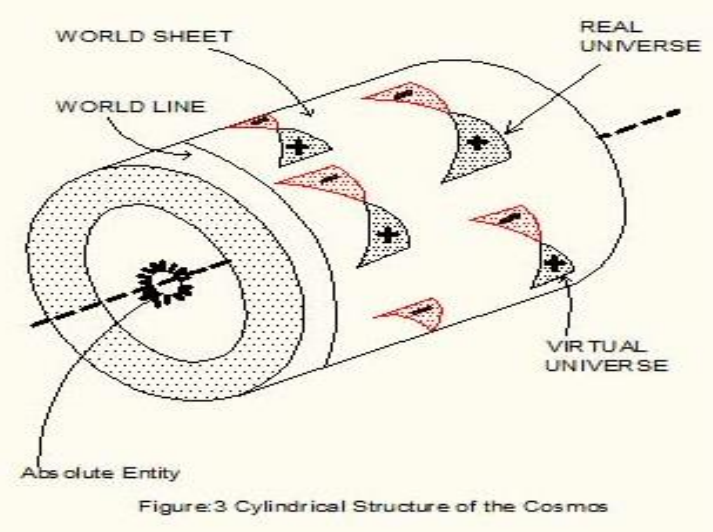

Fig. 2 Cylindrical Structure of Cosmos.

Purush needs no nervous system or organs for controlling their operations. Purush has a Macrocosmic Universe and Cosmic Mind within itself. Nothing is beyond the scope of the Cosmic Mind i.e., everything comes within its mental scope. With the five manifested fundamental physical factors such as Ethereal, Arial, Luminous, Liquid and Solid the Cosmic Mind of the Purush Entity displays its will [7].

\section{B. Prakriti}

The Prakriti is existed even before the big-bang event. It consists of three subtler elemental forces known as sentient (sattwa), static (tamo) and mutative (neutral). There created, in the beginning, multi-sided different shapes in celestial bodies due to nature driven haphazard directional flow of three above cosmic forces (sentient, mutative and static) of Prakriti. In the beginning these three subtler elemental forces in a balanced form like an equilateral triangle. Later, all of a sudden, a triangle of forces of sentient, mutative and static forces started swirling around Omega Point, the portion of Purush (Fig. 3).

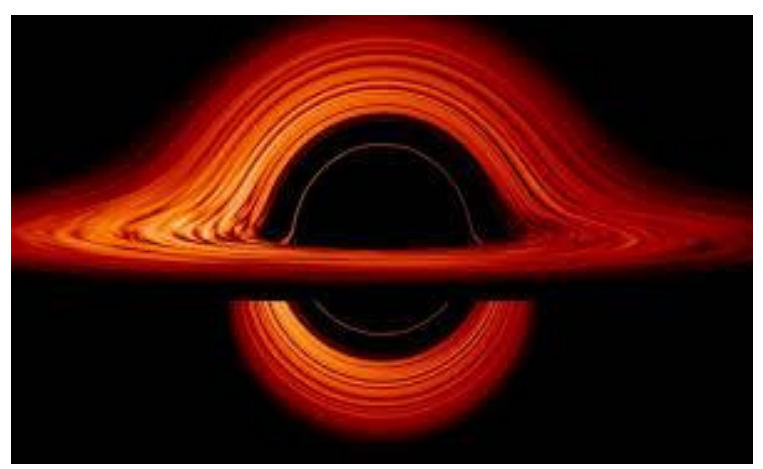

Fig. 3 Prakriti's three forces swirling around omega point in the Black hole.
Each and every matter of Visible World has its anti-matter in unseen form which remains in the Parallel World of Prakriti. There are some additional invisible dimensions exist where something strange was going on. These additional dimensions are so small that it cannot be seen by our physical means. These types of anti-matter are not in a material form but are in wave fluxes of which existence cannot be seen face to face but perceived. The reason is that the dimension of prakriti remains in very small curved space something like a million, million, million, million, and millionth of an inch [8]. These could be said as a transcendental or spiritual form. These are so subtler that they cannot remain in material form but remain as quality or thought/wave form. The entire Cosmos is filled with these elements. They are in a curve shaped having length equivalent to nearly Plank's Constant [2] i.e., invisible form like a one dimensional curved string of Hawkins's String Theory. Human's Unit Mind can enter into the curved quantum strings and can go anywhere swiftly at any place through the dimension of Parallel World. According to Theory of Everything of Stephen Hawking, all empty looked like space is filled with the pair of matter (virtual) and anti-matter which inherits an immense power, and due to its strong gravitational force, all matters and antimatters dense to a single point like a condition before the bigbang of universe as in the Black-holes.

Prakriti has both the positive and negative entity in it but as a whole negatively charged. This does obey spiritual laws but does not follow the physical laws completely. It can do miracles as superpower does. These subtler dimensions could be realized through the inner insights with meditation. Without achieving those capabilities with deep meditation, one may not be able to explain the facts of mental and spiritual dimensions in real sense. Visible World is actually the projection of the Invisible Parallel World of Prakriti after the Big-bang (Nada). Physicists or scientists have to look beyond their mathematical equation or number, and structure of the human body, their eyes, and brain or building blocks of life, not only in the four physical boundaries but towards subtler one also. Besides four physical dimensions it tried to locate other seven subtler dimensions which could solve the clues of the whole universal functions along with the matter, energy, life and ultimately know the God [7]. Although the principles of metaphysics have helped in this regard, but not all scientists are in agreement.

\section{PARALlEL WORLD}

Parallel World is also a part of Prakriti. The part of Prakriti where all the matters and antimatters are condensing towards a point before the Big-bang is known as Sagun Bramh or Parallel World. It is nothing but a process of formation of Black-hole (Fig. 7). Parallel World is contracting Invisible World which is negatively charged whereas Visible World is the expanding world after the Big-bang with positively charged matters. Contracting matters and antimatters of Prakriti and Visible World after Big-bang symbolically make a hexagon triangle like structure without touching each other and come into life and become active to work together. This hexagon triangle of Sagun Bramh is also a symbolic representation of knowledge and it is a symbolic figure of 
many universities, schools, and countries' logos in the world. Actually, it represents the function of both the Visible and Invisible Parallel World (Fig. 4).

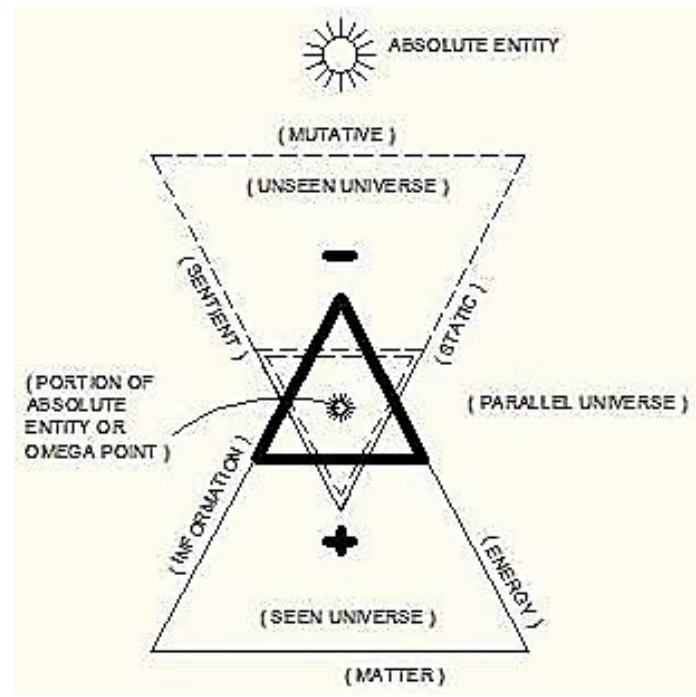

Fig. 4. Parallel World.

\section{CREATION OF Visible WORLD}

Scientists have proposed different theories and models regarding the creation of universe and concept of Purush (God). Most of these theories and models are incomplete solutions to zigzag puzzle shows because they do not fully solve the clues of the formation of universe. Among them are standard big-bang model, steady state model, oscillating model, vacuum fluctuation model, chaotic inflation model, quantum gravity model and super naturalist alternative etc. [11].

Scientists believe that the Big-Bang Model is nearer to the truth in context to the creation of universe. The author believes that the explanation of Big-Bang for the universe creation remains incomplete until the transcendental knowledge supports a complementary roll to the said model. In this regards, the author has tried to propose a complete solution forwarding complementary explanations of parallel universe, Vedas concept of universe formation, Sarkar's Sristi Chakra, Quantum Mechanics, Law of Information and Uncertainty, DNA, String Theory and Buddha's Concept to ease flow of Big-Bang Model [2].

All the modern scientific development and activities are limited only to the Visible World. Scientists believe that some natural forces might be accidently responsible to cause the Big-Bang and create the whole physical Visible World.

There is Invisible Parallel World just before the formation of Visible World which is overall negatively charged. Due to a causal condition, a small portion of the Purush appears in the form of the "omega-point" in singularity condition in the black-holes with a brilliant white light which disturbs the equilibrium of three kinds of forces of Prakriti. Thus, the part of Purush attains the state of perfusion. It is through this resultant force the "Sagun Brahma" (Brahma with quality) incarnates himself in the Visible World. Thus, the two eternal entities Purush and Prakriti go on to form the Visible World together with other living beings. The point from which the resultant force erupts is called the "Nada" or a "Big-bang". With the Big-bang, Sagun Brahma in singularity condition explodes and spreads over time, creating universes and celestial bodies such as the space, air, fire, liquid and solid matter and later galaxies, black-holes, stars, planets, and satellites, over a period of 13.6 billion years (Fig. 6).

Now, in the next steps Prakriti expressing herself in the form of the resultant force inculcates a feeling of "existence" or "I" feeling in the entity which is known as "Mahattattva". At this stage, the creation of existence feeling occurs in the entity which does not have thinking or doing ability. Sentient force of Prakriti is gradually transformed into the mutative principles owing to its internal clash. This mutation causes the feeling of second subjectivity and so the cosmic "I" gets metamorphosed into the cosmic doer "I". This cosmic doer "I" is known as "Ahamtattva" (Ego; or second mental subjectivity). At this stage entity will have a knower-ship only. Thus, the Ahamtattva exists only in subjective strata. As the static principle starts its domination Ahamtattwa gets objectivity. At this stage an entity will have doer-ship quality also and thus Chitta comes into existence. Chitta (Mind) under the influence of static force gets cruder and at a later stage is transformed into the Microvitum which is a kind of subtler living entity in the form of idea or thought. This Microvitum could be the genetic mutative force which has been discovered in the modern quantum physics as a "mysterious" "transcendental realm" beyond normal spacetime. This appears to be the source of driving force behind evolution of our life system in universe. This is the silver lining between the spiritual and psychic (antimatter and matter) stage and cannot affect the spiritual structure but can affect both the physical and psychic structures. It is a living subtler organism responsible for converting the idea into matter or energy and life indirectly as well. It is more idea than matter [6]. Static forces metamorphosis Microvitum into ethereal element first. In this case "sound" remains as fluxes (fractions of wave). Arial element comes into existence and in this "sound" and "touch" remains as fluxes. Then Luminous is created whose fluxes are "sound", "touch" and "shape". And then liquid is created, and its fluxes are "sound", "touch", "shapes" and "tests". Finally, solid element is created, and "sound", "touch", "shapes", "tastes" and "smell" remain as its fluxes. Solid is the crudest manifestation of Purush (Fig. 5). The physical unit structures are composed of five fundamental factors - ethereal, aerial, luminous, liquid, and solid. All these factors should remain in required proportion and on the mutual cohesion amongst these factors depends upon the resultant interial or the Pranah (vital energy of life). The controlling nucleus of all these fundamental physical nuclei is the controlling points of collective prana. This collection of prana is called "Pranah" or "vital energy". The detailed nature and functions of these invisible dimensions are shown in Table I.

Within a fraction of second after the Big-Bang, all the known four physical forces of Visible World such as strongest sub-atomic (gluon), weak sub-atomic (radiation), electromagnetic and gravitational forces were created. 


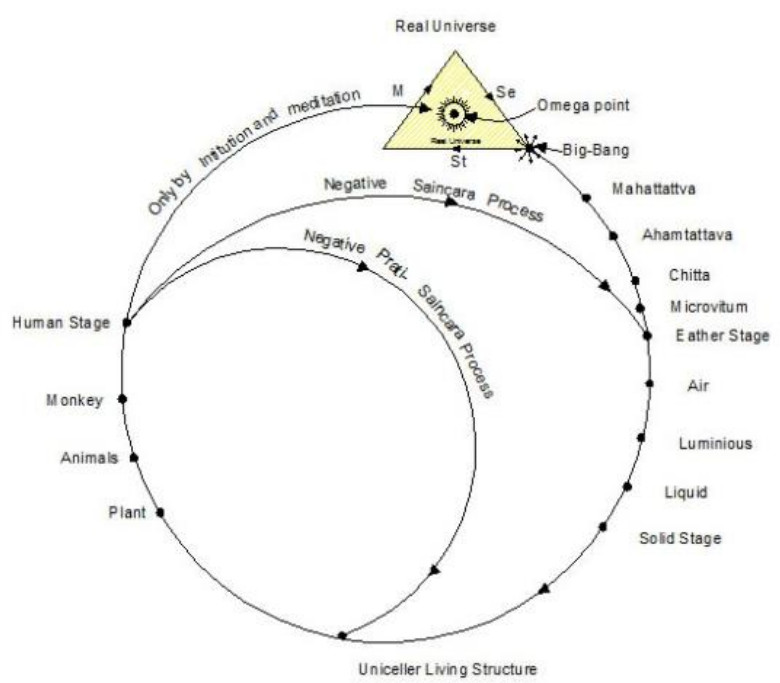

Fig. 5. Sristi-Chakra with Big-bang.

In the earlier moments after the Big-Bang, the weaker gravitational force, as time passed, started dominating among forces, and as a result created bigger lumps of celestial bodies commenced attracting scattered small particles into their orbits. Wherever particles were produced, anti-particles were generated immediately after. Being opposite to each other, they collide and destroy themselves which is going on continuously in space. The collided particles ultimately attracted by the black-hole. Some of these particles get ejected from the black-holes and get scattered out into far space. Hawking state that the universe contained no empty space, some process of regeneration and destruction of particles were going on in the space. Black-hole present in space is not completely black as they assumed before. There is not only unseen matter, but some seen matter is also present in scattered form. In the black-hole there is more than $99 \%$ of unseen matter which is known as black or dark-matter releasing the radiation completely which is getting evaporated. Therefore, ultimately it will vanish into space in course of time which is known as Hacking's Radiation. According to Hawkins our universe is expanding and all the matters in the universe are speeding away from each other becoming faster as they go further away. The main reason of the expansion is due to black energy. Black energy is homogenously distributed throughout the universe; not only in space but also in time, in other words, its effect is not diluted as the universe expands. This leads to a repulsive force, which tends to accelerate the expansion of the universe. The dark-matter creates the gravitational force whereas contrary to this black-energy produces an ant-gravity force. Due to this black energy the star clusters are pushed away slowly towards the end of the universe. During this course some galaxies are also merged into other galaxies creating bigger one. For example, Andromeda galaxy is approaching towards our galaxy (Milky Way) and one day it will collide to make bigger lumps to form bigger galaxy. Cosmic evolution creating further the ions, electrons, protons, atoms, and later heavy elements along with the inorganic, organic elements and then with complex molecules with carbon atom and ultimately life in the Visible World (Fig. 6). Later according to Durbin's theory, complex life has been created such as monkey, champagne and finally complex human into existence (Fig. 5). In this way, due to the repulsive forces of black energy, all the celestial bodies of our galaxy (Milky Way) also disappear into deep space someday.

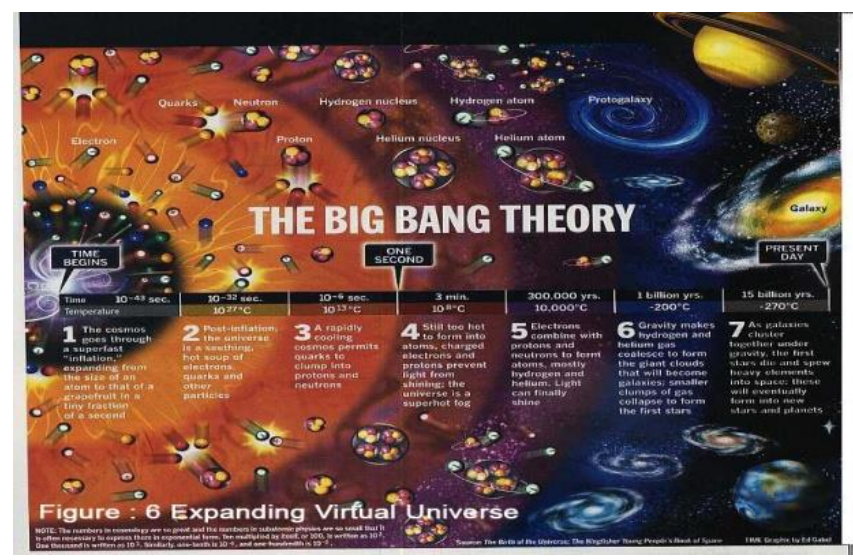

Fig. 6. Expanding Virtual Universe. Source: The birth of the Universe, The Kingfisher Young People's Book of Space

The Black-holes could be compared with the Sagun Bramha. On the upper side of the Black hole there is a Parallel World which illuminates during the singularity condition of the three forces of sentient, mutative and static. During its singularity condition it is in lighted with white light (Photon) as seen in Sagun Bramha. Thus, the beginning of the universe is taken place as mentioned above from the Sagun Bramha [8]. Fig. 7, 8 and 9 clearly shows the Black-hole formation before the Big-bang. On upper side of the Big-bang we have invisible parallel world where all the dark matter and celestial bodies attracted towards a point which illuminates later as an omega point when reaches to singularity condition. After Bigbang it projects the visible world on other side. Thus, this is a kind of infinite process of formation of black-holes and Visible World. There could be many such black-holes in the universe which could explode with Big-bang and create a new Visible Worlds. Physical constant may exist in different galaxy with the equation which we do not know yet at present. Thus, the process of black-hole formation and the big-bang remains continued forever.

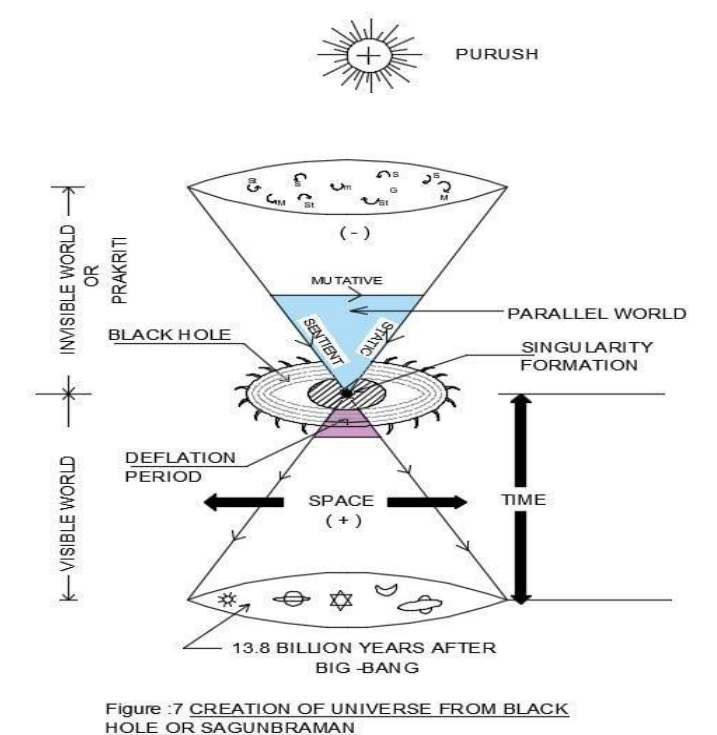

Fig. 7. Big-bang of Black hole and formation of Visible World. 


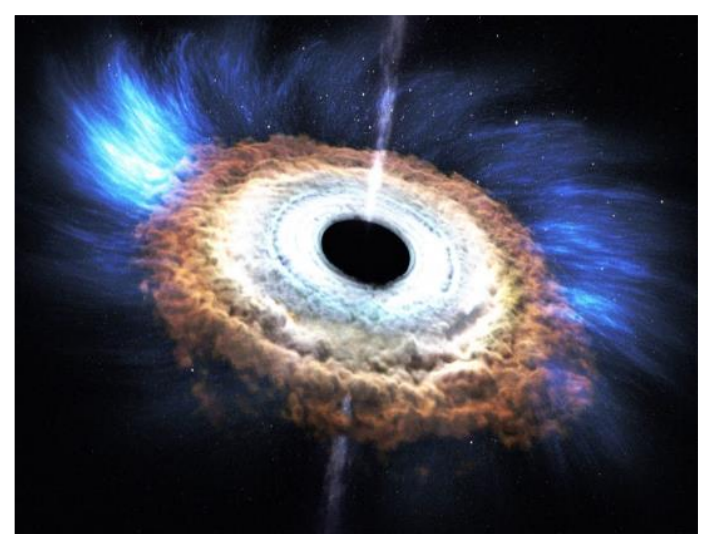

Fig. 8. Black hole in singularity condition.

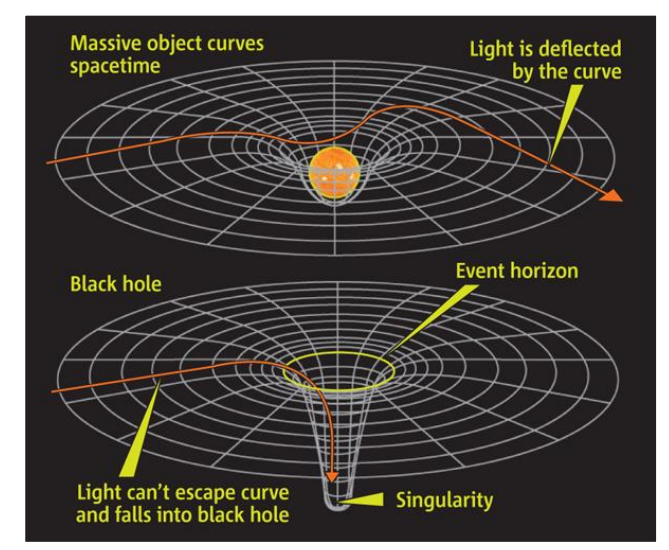

Fig. 9. Singularity condition in Black-hole.

Our brains have in average 100 billion neurons. Harmeroff and Penrose have produced the meditating condition in micro tubes of human brain reacting with the quantum. According to their theory due to production of quantum coherence in the micro tubes of brain it starts separating and later it coincides with its threshold quantum gravity. Thus, with its continuous impacts it shows immediately the present incident. Thus, due to continuous such incident it can regulate time dimension to past, present, future and towards the meditating condition. At the same time, it can enlighten the internal photon which we call internal light of brain. This is real and based on the human's virtual cellular which also shows the human's systematic action.

Russian scientist Dr. Pijoter Garjajev has found that the molecule of DNA can produce the photon light in a length of ultraviolet rays. A bacteria talk with other bacteria through the help of light. This is a kind of wireless internet which is based on DNA. This kind of communication is performed not only in cell to cell but among the animal to animals also. This can be seen especially in the folks of birds flying in line with certain pattern in sky or fishes swimming in seas with different patterns. Photon can control all activities. According to F.A. Pop the bio-photon and light are produced from the DNA. Therefore, DNA is the master turning fork. It can control fixed types of molecules of our body with one kind of frequency while with other frequency it controls other kinds of molecules.

The physical science does not have all the necessary dimensions to answers all the existed unseen dimensions. We need some extra-dimensions besides space and time. Human mind and its wave are so subtler that it could go to anywhere within no time. It can move thousand times faster than speed of light. Normally the human brain emanates irregular rhythms called beta waves. Repeating a special sound during meditation it creates a calm vibration that stills the restless human mind. Gradually, the brain waves slow down to calm rhythmic alpha waves and the mediator enters a state of deep and serene concentration. With continued concentration on the brain waves slow down still further to "theta waves" and tremendous psychic energy builds up inside the mind (Fig 10). By meditation man can improve it to a theta wave. Theta wave has a length of infinity, and this is the wave of invisible Prakriti and Prush entity which is spiritual in nature.

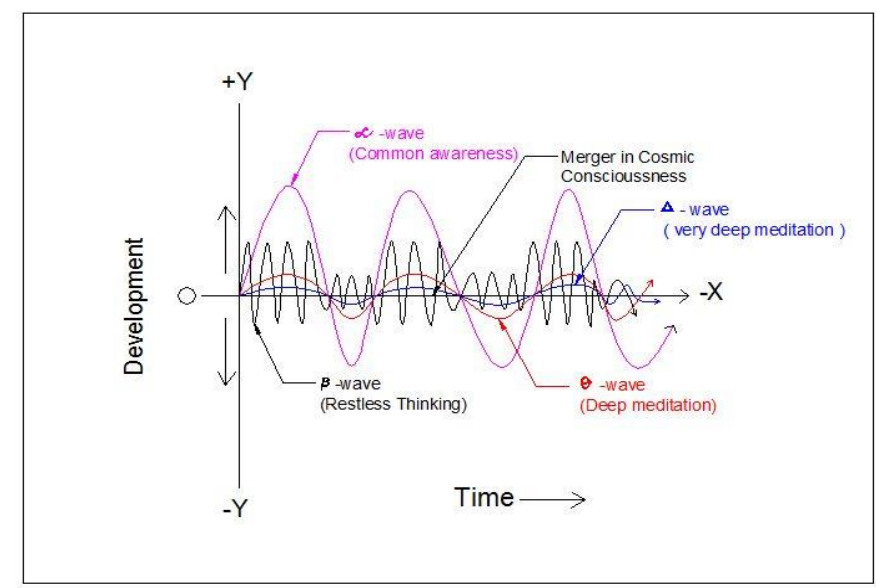

Fig. 10. Alpha, Beta, Delta, and Theta Waves.

The creation and operation of the universe and the living worlds have a role of three kinds of sciences, such as Spiritual or Abstract, Mental (psychiatry) and Physical. Spiritual or Abstract science inoculates "Purush" and "Prakriti" dimensions in an entity, while Mental science inoculates another five invisible dimensions such as mahat-tattva, aham-tattva, chitta-tattva, microvita, pranah, and physical science inoculates space and time dimensions in an entity and living beings. Mental science also creates another five different kinds of consciousness (kosh) in an entity such as Kammaya or Pranamaya kosh, Manmaya or Annamaya kosh, Atimansa kosh, Vijnanmaya kosh and Hiranyamaya kosh (Fig. 11). The unicellular organisms or objects that live on food only have manmaya or annamaya kosh, but man has all five types of koshas within himself, but in order to activate the hiranyamya kosh, special efforts have to be made by man through meditation.

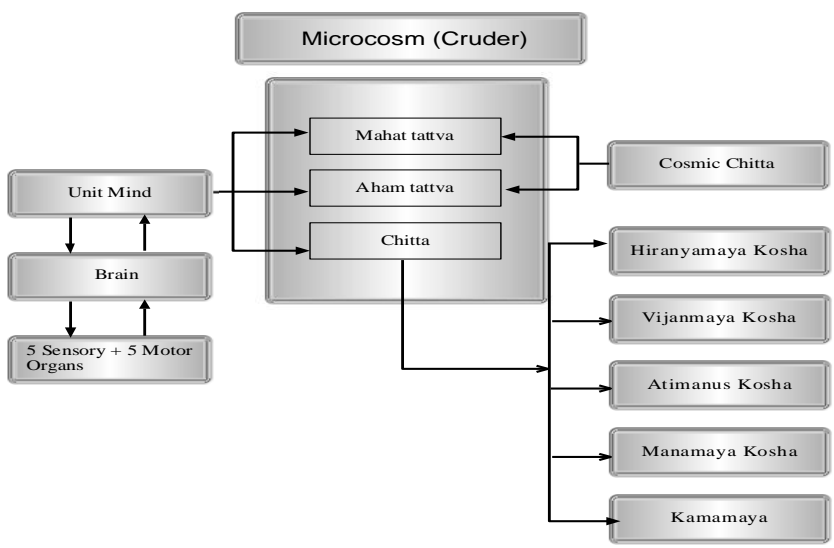

Fig. 11. Microcosmic World. 
The physical body is burned or buried in earth after the death of a person, and thus the physical body gets destroyed. Soul of human which is a spiritual in nature is a witness entity keeps and tracks all records of works done and information's in the physical world by a unit mind of a person or object in space and time like an invisible super computer cheeps. But the Soul remain intact with all its characteristics and information's earned in Visible World remains in Parallel World, and whenever it finds suitable physical structure, it enters into as a suitable physical body to get rebirth again in Visible World. British neurologist John Eccles concluded that human consciousness was extra-cerebral and that the nonphysical mind entered the physical brain during embryological development [5].

TABLE I: ELEVEN DiMENSIONS OF CREATION AND THEIR FunCTIONS HAVE BEEN LiSTED BELOW [7]

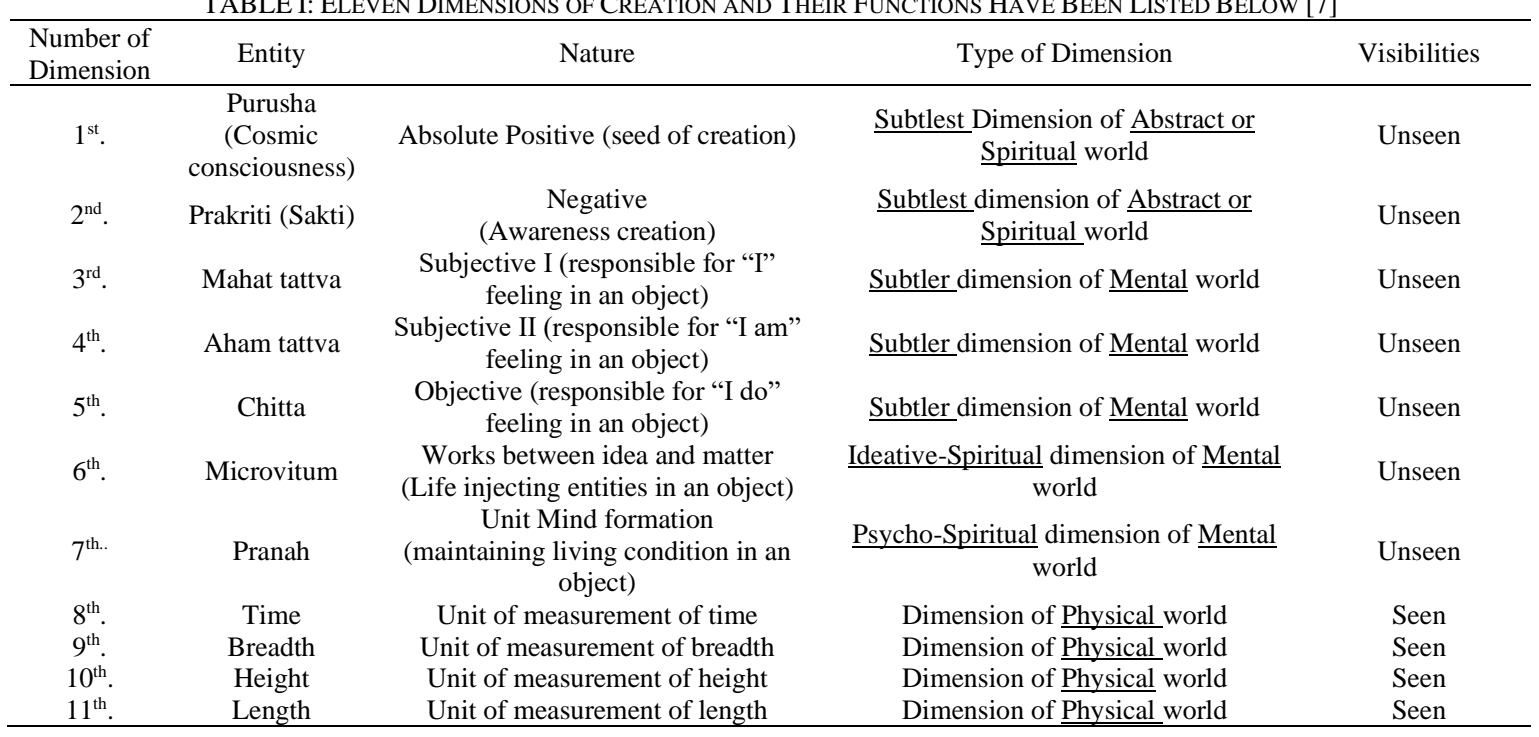

\section{CONCLUSION}

Entire cosmos consists of two entities, Purush and Prakriti. Purush exists at the centre of the cosmos having pure positive in nature are also called as Nirgun Bramh (qualitiless Bramh) or Shiva or Cosmic consciousness or Absolute entity while Prakriti is negatively charged entity with its three kinds of thoughts waves (sattwa, rajas and tamas). Prakriti and Purush both obey spiritual laws but does not follow the physical laws completely. It can do miracles like a superpower does. All three worlds such as physical (having 4 dimensions), mental (having 5 dimensions) and spiritual or Abstract (having 2 dimension) are present at human development stage and it is mathematically synchronized in symmetrical ways. We exist inside the black-hole. There are many black-holes in the universe which explode with Big-bang and create new Visible Worlds. Physical constant exists in different world with their equation which we do not know yet. Visible World follows the physical and mathematical laws completely with great precessions.

Word is made of different kinds of vibration of strings. The vibration of words or sounds produces all physical particles and elements in the Visible World. If there is a matter or motion or any kind of activities exists, there must be some kinds of sound or bits going on.

On the upper side of the Black-hole, we have a Parallel World which illuminates during its singularity condition known as Sagun Bramha (Bramh with quality). The beginning of the universe is taken place from the Sagun Bramha with Big-bang. On upper side of the Big-bang point there is Parallel World where all the dark matter and celestial bodies attracted towards a point which illuminates when reaches to singularity condition. After Big-bang it projects the Visible World on other side. Thus, this is a kind of infinite process of formation of black-holes and Visible World. There could be many such black-holes in the universe which could explode with Big-bang and create a new Visible Worlds. Information acquired at Visible World could be recovered after death of physical body somewhere from Parallel World.

Physicists or scientists have to look beyond their mathematical equation not only in the four physical dimensions but towards another seven invisible subtler dimensions which could solve the clues of the whole universal functions along with the matter, energy, life and ultimately know the God. These subtler dimensions could be realized through the inner insights with meditation. Without achieving those capabilities, one may not be able to explain the facts of mental and spiritual dimensions in real sense. Meditation is the process practiced by Unit Mind (mind of a person) to reach near to Cosmic Mind (mind of Purush). It is in this sense that Consciousness is transcendental to the manifested universe. The universe exists in Consciousness like future wave in calm sea-only apparently different in potentiality. No substance of Cosmos could be lost or destroyed, but only it changes from potential to the movement forms depending upon their casual condition, and that is when Consciousness-at-rest transforms to Consciousness-in-action, when Potential Energy becomes actual energy.

\section{ACKNOWLEDGEMENT}

Author thanks and acknowledge all the great philosophers, scientists, relevant institutions, research centers, magazines, media, and scholars, prophets of all religions whose views have been incorporated in this manuscript and to P.R. Sarkar whose initiation has inspired this write up. Author also thanks Er. Ameresh Man Shrestha for designing illustrations of the manuscript. 


\section{REFERENCES}

[1] Balsekar, R.S. Consciousness Pervades the Real and Unreal. The Times of India.http://spirituality.Indiatimes.com. $20 \mathrm{Feb} .2008$.

[2] Cheodon, 1., Cosmology Concept in Buddist Philosophy.Paperpresented at Tribhuvan University, Kathmandu, Nepal. 21 March 2012

[3] Hawking, S.W. and Penrose, R. Nature of Space and Time. Princeton University Press. 121 pp. 1996.

[4] Hawking, S.W. The Theory of Everything. Jaico Publishing House, Mumbai, India. 132, pp. 2007.

[5] Kundu, M.N. Exploring consciousness Beyond Body and Mind. Times of India, 19 July, 2005

[6] Sarkar, P.R. Microvitum in a nutshell. Ananda Marga Publications. Culcutta, India. 158 pp Third edition. 1991.

[7] Shrestha M.M. The development Dimension, A Converging Point of Eastern \& WesternPhilosophy and Science. Usha Publication, Lalitpur, Nepal. 234pp. 2009.

[8] Shrestha M.M. The Secrecy of the Universe: The Theory of Absolutivity, Human and Social Science at the common conference (HASSACC), Slovakia. Nov 17-24, 2014.

[9] Mahesh Man Shrestha, Universe and God (A scientific analysis), 2019, Usha Publication,46, Lalitpur, Nepal; 251 pp Kathmandu, Nepal (in Nepali).

[10] Taneja, A. Entire Cosmos is in human body. The Times of India, 6 March 2009.

[11] William L.C. The Ultimate Question of Origins: God and the Beginning of the Universe. www.reasonablefaith.org.

[12] Yoga_Vasistha. en.wikipedia.org/wiki/.

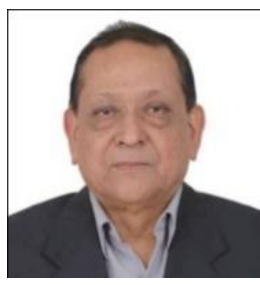

Mr. Mahesh Man Shrestha was born on 11 April 1945 in Kathmandu, Nepal. He has served the Government of Nepal as a secretary in the Ministry of Science and Technology, Govt. of Nepal. He has earned M.S. in Engineering (Irrigation and drainage Engineering) from Utah State University, Logan, USA in 1976.

His publications are as follows:

1. Shrestha M M, Evolution of life, death, rebirth: The theory of Absolutivity, Human and Social Science at the common conference (HASSACC), The 3rd Human and Social Sciences at the common conference, Slovakia. October 5-9, 2015.

2. Shrestha M M, The Secrecy of the Universe: The Theory of Absolutivity, Human and Social Science at the common conference (HASSACC), Slovakia. Nov 17-24, 2014.

3. Shrestha M M, Secrecy of the CERN- Theory of the Absolutivity: Human and Social Science at the common conference (HASSACC), Slovakia. Nov, 2018. 